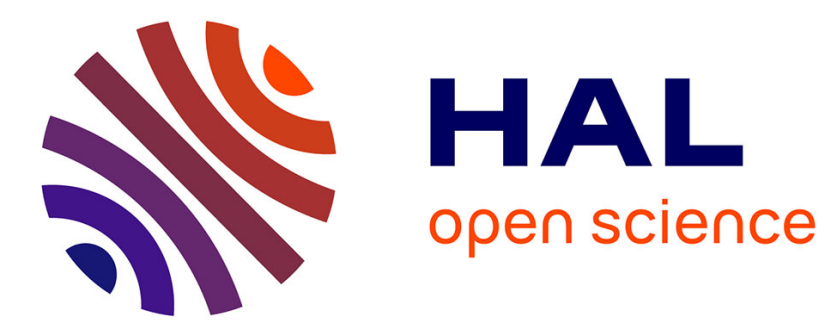

\title{
3D multi-resolution mapping of Valles Marineris to improve the understanding of RSLs
}

\author{
Yu Tao, Greg Michael, Jan-Peter Muller, Susan Conway
}

\section{To cite this version:}

Yu Tao, Greg Michael, Jan-Peter Muller, Susan Conway. 3D multi-resolution mapping of Valles Marineris to improve the understanding of RSLs. 14th Europlanet Science Congress 2020, Oct 2020, held online, Unknown Region. 10.5194/epsc2020-430 . hal-03091573

\section{HAL Id: hal-03091573 \\ https://hal.science/hal-03091573}

Submitted on 7 Jan 2021

HAL is a multi-disciplinary open access archive for the deposit and dissemination of scientific research documents, whether they are published or not. The documents may come from teaching and research institutions in France or abroad, or from public or private research centers.
L'archive ouverte pluridisciplinaire HAL, est destinée au dépôt et à la diffusion de documents scientifiques de niveau recherche, publiés ou non, émanant des établissements d'enseignement et de recherche français ou étrangers, des laboratoires publics ou privés. 
EPSC Abstracts

Vol. 14, EPSC2020-430, 2020

https://doi.org/10.5194/epsc2020-430

Europlanet Science Congress 2020

(C) Author(s) 2021. This work is distributed under

the Creative Commons Attribution 4.0 License.

\title{
3D multi-resolution mapping of Valles Marineris to improve the understanding of RSLS
}

\author{
Yu Tao ${ }^{1}$, Greg Michael ${ }^{2}$, Jan-Peter Muller ${ }^{1}$, and Susan Conway ${ }^{3}$ \\ ${ }^{1}$ University College London, Mullard Space Science Laboratory, Space and Climate Physics, Dorking, UK \\ ${ }^{2}$ Freie Universität Berlin, Berlin, Germany \\ ${ }^{3}$ Laboratoire de Planétologie et Géodynamique, Nantes, France
}

\begin{abstract}
In this work, we demonstrate techniques and results of a 3D mosaic of the whole of the Valles Marineris (VM) area of Mars using stereo images from the Mars Express High Resolution Camera (HRSC), as well as some examples of multi-resolution orthoimage and 3D mapping of 3 selected sites where recurring slope lineae (RSL) are common, at Coprates Montes, Nectaris Montes, and Capri Chaos, using Mars Reconnaissance Orbiter (MRO) Context Camera (CTX), High Resolution Imaging Science Experiment (HiRISE) and the Compact Reconnaissance Imaging Spectrometer for Mars (CRISM).
\end{abstract}

\section{Introduction}

Valles Marineris is the largest system of canyons on Mars that is more than 4,000 km long, $200 \mathrm{~km}$ wide, and up to $10 \mathrm{~km}$ deep. 3D mapping is essential to improving our understanding of the geological environment of Valles Marineris. Typically, deriving a co-aligned and mosaiced 3D base map covering the whole area is generally the starting point of such studies. This work focuses on a demonstration of multi-resolution 3D mapping and co-alignment of different data sources over the VM area using a co-registered and nested HRSC-CTX-CRISM-HiRISE dataset.

\section{D modelling}

Previously, within the EU FP-7 iMars (http://www.i-mars.eu) project, we developed an automated multi-resolution Digital Terrain Model (DTM) processing chain for NASA CTX and HiRISE stereo-pairs, called the Co-registration ASP-Gotcha Optimised (CASP-GO), based on the open source NASA Ames Stereo Pipeline (ASP) [1], tie-point based multi-resolution image co-registration [2], and the Gotcha [3] sub-pixel refinement method. The CASP-GO system guarantees global geo-referencing congruence with respect to the aerographic coordinate system defined by HRSC, level-4 products and thence to the MOLA DTM, providing much higher resolution stereo derived DTMs.

\section{D area mosaic using HRSC}

HRSC is now on its $\sim 5,700^{\text {th }}$ orbit onboard Mars Express, (totalling $>20,000$ HRSC products) covering $\sim 98 \%$ of the Martian surface at a spatial resolution higher than $100 \mathrm{~m} / \mathrm{pixel}$. Among these, DLR has processed HRSC stereo images (level 4 DTMs, [4]), at 50-150m/pixel resolution, that now cover 
$\sim 50 \%$ of the planet's surface. At Valles Marineris, the DLR HRSC level 4 DTMs have covered a large portion of the canyons, leaving several large gaps unprocessed or having missing data.

We created a further 11 HRSC single strip DTMs and Orthorectified images (ORIs) using HRSC level 2 stereo images to cover these gaps. These are processed using CASP-GO [2] and co-registered with the existing DLR HRSC level 4 DTMs and ORIs to allow seamless mosaicing for the whole of Valles Marineris. Also, to eliminate the need for bundle block adjustment, both UCL and DLR HRSC level 4 DTMs are co-aligned with the MOLA DTM using an iterative closest point co-alignment which is part of ASP [1]. Figure 1 shows a colourised and hill-shaded DTM of the whole area. HRSC level 4 ORIs are then generated using this mosaiced DTM are radiometrically corrected and brightness/contrast adjusted to produce a corresponding HRSC ORI mosaic [5].

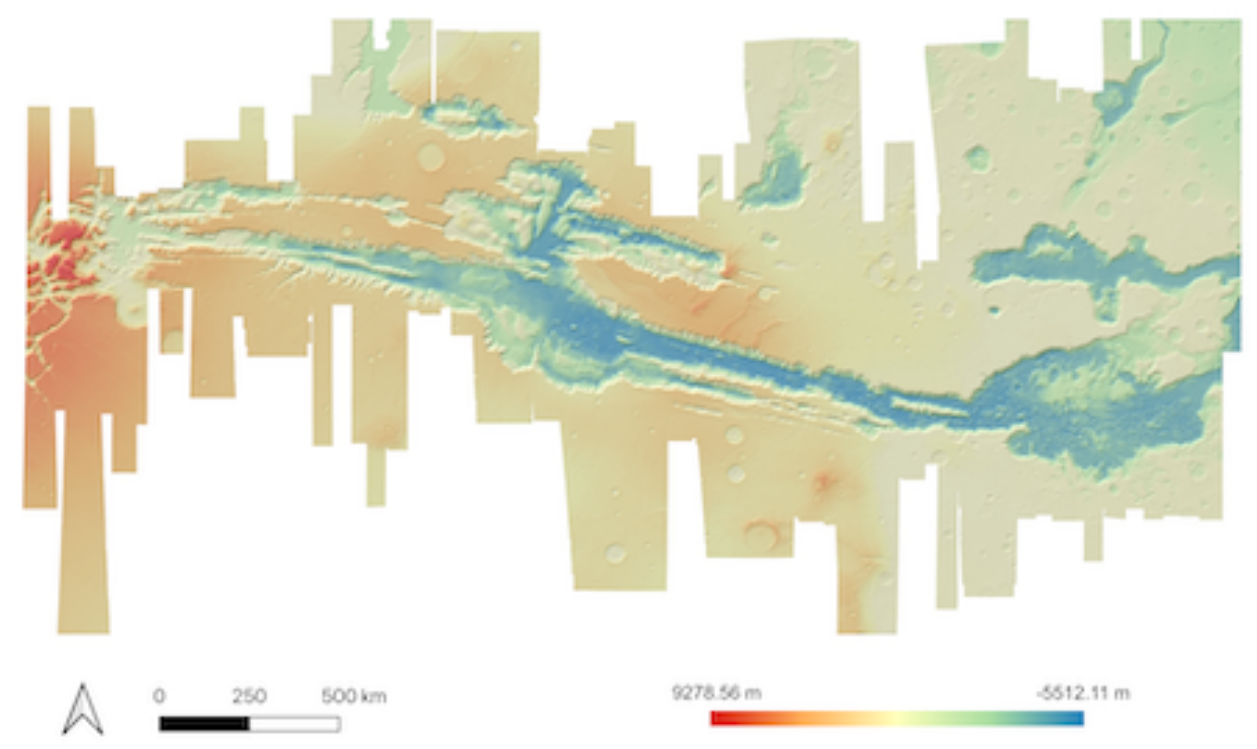

Figure 1 HRSC DTM merged DLR + UCL mosaic of VM at 50m/gridpoint 


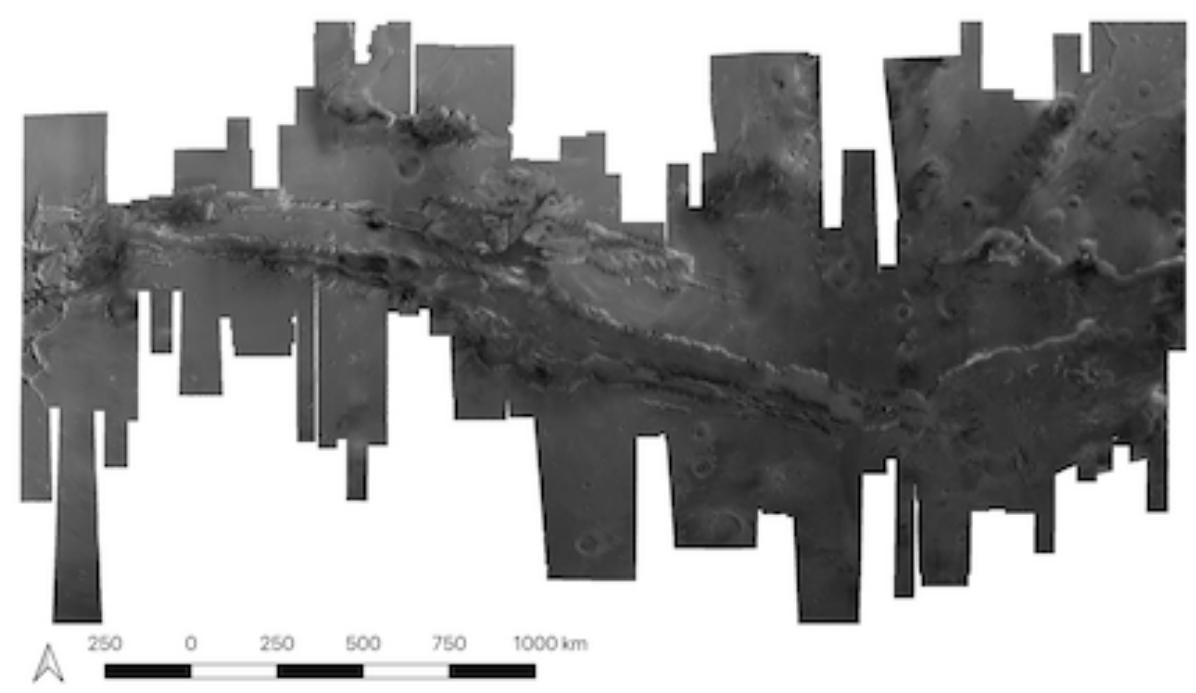

Figure 2 HRSC ORI mosaic of VM generated at $12.5 \mathrm{~m}$ after brightness adjustment [5]

\section{Automated co-registration of CTX, HiRISE and CRISM}

In order to study RSL features, we produce stacks of multi-resolution products using the HRSC DTM and ORI as the basemap. We here show an example of one of the CTX DTMs and ORIs for Capri Chaos which is one of the three selected study sites. The CTX ORIs are co-registered with the HRSC ORI mosaic using the tie-point based image co-registration pipeline described in [2]. The CTX DTMs are then spatially adjusted according to the ORI tie-point and co-aligned vertically to the HRSC DTM mosaic using a B-Spline fitting method to eliminate any residual jitter. The spatial agreement between CTX ORIs and HRSC ORI mosaic is at subpixel level of the base image $(\sim 5 \mathrm{~m})$. The vertical agreement between CTX DTMs and HRSC/MOLA DTM mosaic can be reduced from several hundreds of metres to less than $10 \mathrm{~m}$ (on average) and $50 \mathrm{~m}$ (at maximum).

Subsequently, we have also corrected the UoA HiRISE ORIs and DTMs using the same joint image coregistration and vertical alignment method to CTX basemap. The CRISM data is also co-registered with the CTX ORI using a modified version of the tie-point based image co-registration pipeline, bringing several hundreds of metres of spatial misalignment to less than 18 metres. An example of the co-registered nested stack is shown in Figure 3 and of the CTX DTM in Figure 4. 


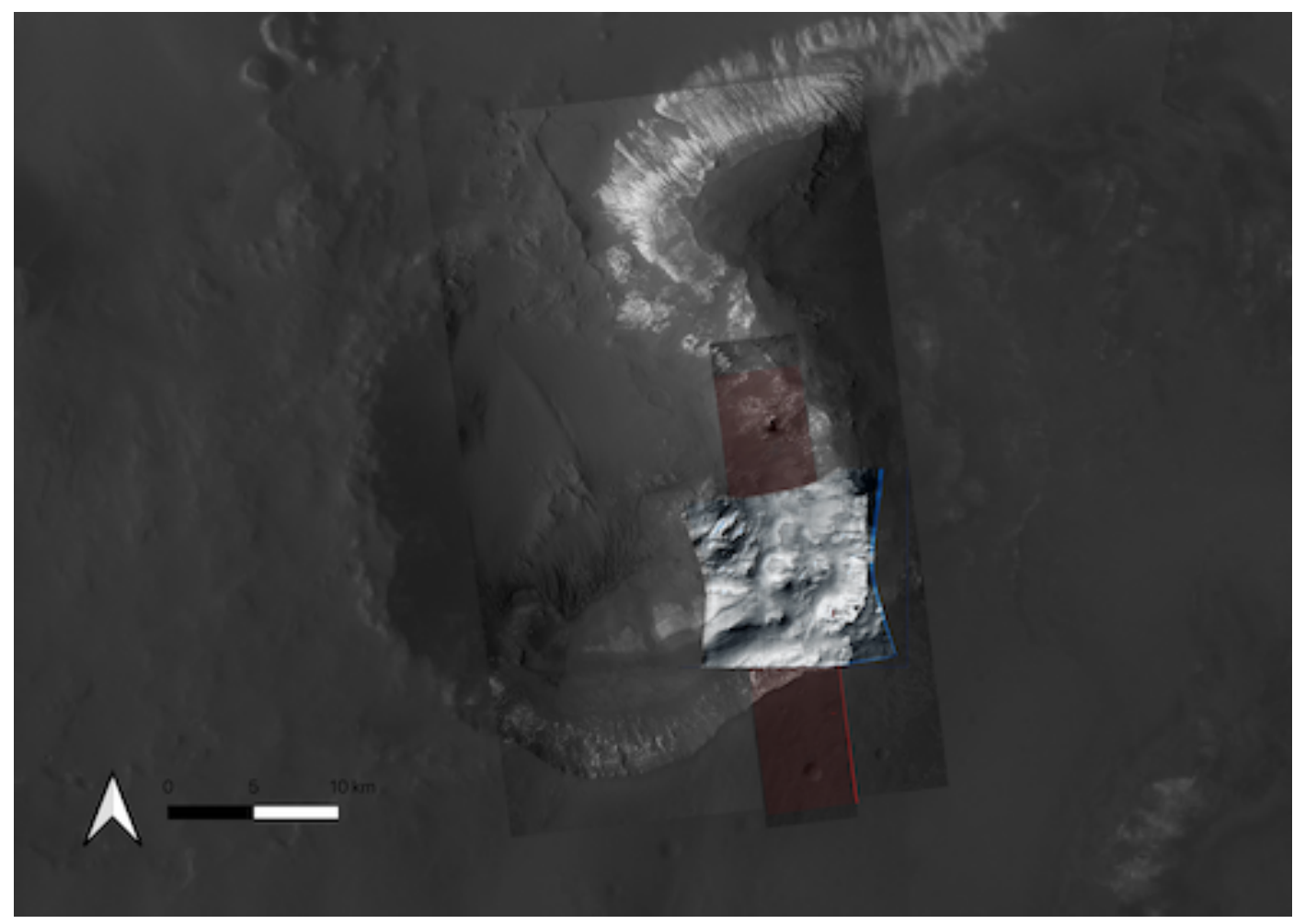

Figure 3 Co-registered HiRISE ORI (at 90\% transparency) and unco-registered UoA HiRISE ORI (in red), co-registered CRISM (at 90\% transparency) and unco-registered raw CRISM (blue) image, shown on top of the UCL CTX ORI and HRSC ORI mosaic at Capri Chaos in the Valles Marineris.

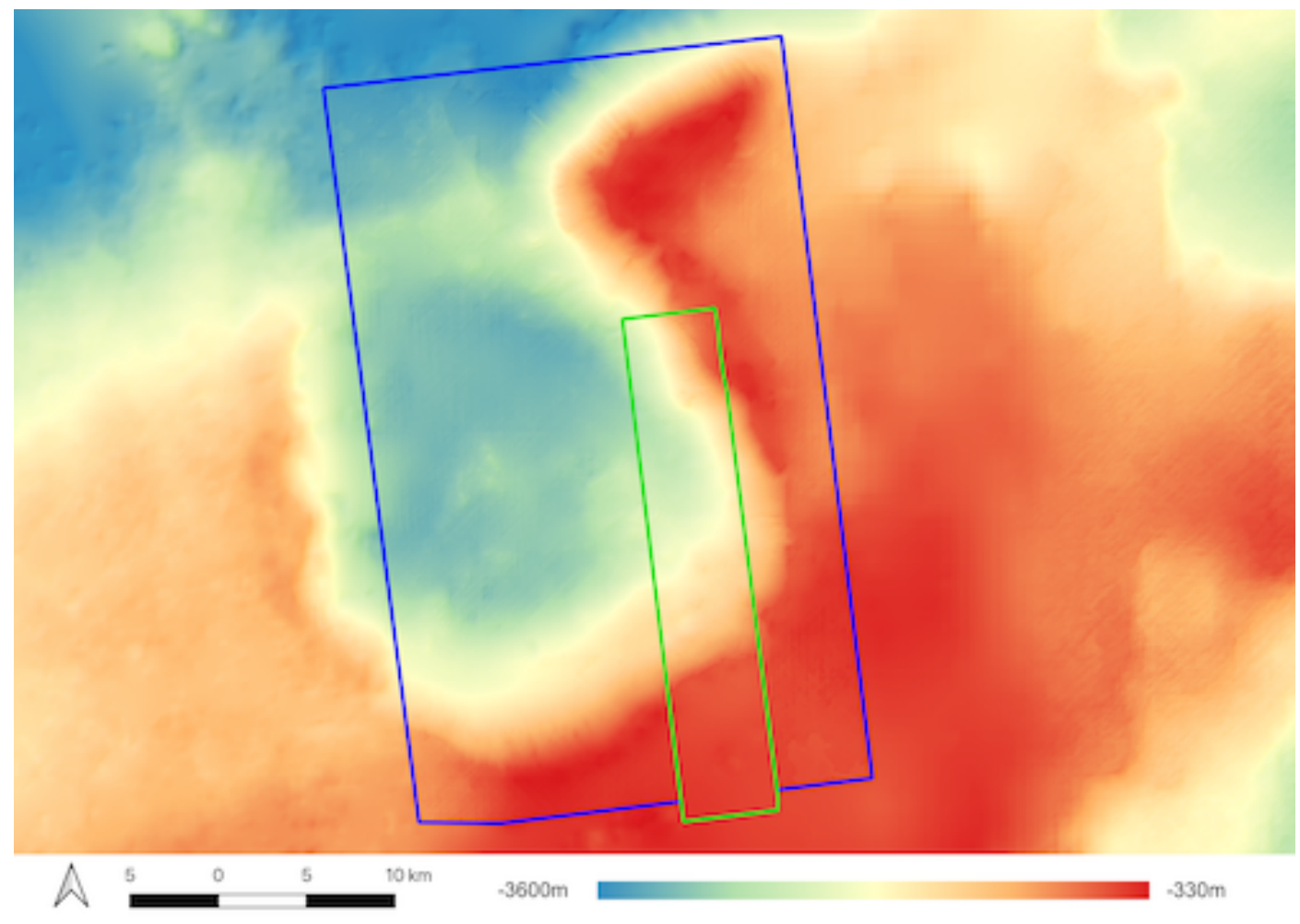

Figure 4 Colourised and hillshaded figures of co-aligned and nested HiRISE DTM (in green bounding box), CTX DTM (in blue bounding box), and HRSC DTM mosaic at Capri Chaos at VM. 


\section{Conclusion}

Precisely co-registered HiRISE, CRISM, CTX and HRSC data will be used as a basis for future comprehensive analyses of RSL sites using: time-series data to track RSL development, topographic analysis to constrain the slopes over which they propagate combined with information from compositional data derived from spectral and photometric data.

\section{Acknowledgements}

The research leading to these results is receiving funding from the UKSA Aurora programme (2018-2021) under grant no. ST/S001891/1. The research leading to these results also received partial funding from the European Union's Seventh Framework Programme (FP7/2007-2013) under iMars grant agreement $n^{\circ} 607379$. SJC is grateful for the financial support of CNES in support of her HiRISE work.

\section{References}

[1] Beyer, R., O. Alexandrov, S. McMichael (2018), Earth and Space Science, vol 5(9), pp.537-548. [2] Tao, Y., J.-P. Muller, W. Poole (2016), Icarus, vol 280, pp.139-157. [3] Shin, D. and J.-P. Muller (2012), Pattern Recognition, vol 45(10), pp.3795 -3809. [4] Gwinner et al., (2016) PSS, vol. 126, pp. 93-138 [5] Michael, G.G. et al. (2016), PSS, vol 121, pp. 18-26. 